\title{
The impact of socio-economic circumstances on overall and grade-specific prostate cancer incidence: a population-based study
}

\author{
K Shafique $^{*, 1}$, R Oliphant ${ }^{2}$ and DS Morrison ${ }^{1,2}$ \\ 'Public Health, Institute of Health and Wellbeing, College of Medical, Veterinary and Life Sciences, University of Glasgow, I-Lilybank Gardens, Glasgow \\ GI 2 8RZ, UK; ${ }^{2}$ West of Scotland Cancer Surveillance Unit, I Lilybank Gardens, Glasgow GI 2 8RZ, UK
}

\begin{abstract}
BACKGROUND: If the observed increasing incidence of prostate cancer and higher incidence in more affluent men are due to differences in diagnostic sensitivity, an excess of asymptomatic low-grade tumours might be expected.

METHODS: We conducted a descriptive population-based study of incident cases of prostate cancer (International Classification of Diseases version 10 codes for prostate cancer) in the West of Scotland, using the Scottish Cancer Registry data from 1991 to 2007. Socio-economic circumstances were measured using the Carstairs score, and disease grade measured using the Gleason score. Deprivation-specific European age-standardised incidence rates were calculated, and joinpoint regression analysis were used to identify significant changes in trends over time.

RESULTS: A total of I 519 incident cases of prostate cancer were diagnosed. Incidence increased by $70 \%$ from 44 to 75 per 100000 cases between 1991 and 2007, an average annual growth of 3.6\%. Men aged $<65$ years experienced the largest increase in incidence. A widening socio-economic deprivation gap in incidence appeared from 1998 onwards in low-grade disease only. From 2003 to 2007, the deprivation gap (affluent to deprived) was 40.3 per 100000 cases ( $P<0.00$ I; trend), with rates $37 \%$ lower among the most deprived compared with the most affluent. This deprivation gap represents an estimated 1764 cases of prostate cancer over a 5 -year period.

CONCLUSION: Prostate cancer incidence continues to increase; an increase in low-grade disease in affluent men may suggest that prostate-specific antigen testing is responsible, but it does not explain the overall increases in all grades of disease.

British Journal of Cancer (2012) I 07, 575-582. doi: 10.1038/bjc.2012.289 www.bjcancer.com
\end{abstract}

Published online 3 July 2012

(c) 2012 Cancer Research UK

Keywords: prostate cancer; incidence; socio-economic inequalities; Scotland; low grade; high grade

In developed countries, prostate cancer is now the most common male cancer, accounting for $11.9 \%$ of the annual cancer burden. Few risk factors are known for prostate cancer beyond age (Sakr et al, 1996), ethnicity (Sakr et al, 1996; Ben-Shlomo et al, 2008) and familial prostate cancer risks, which are greatest among firstdegree relatives (Johns and Houlston, 2003). A greater increase in incidence of prostate cancer in Scotland has been attributed to greater use of trans-urethral resection of the prostate for other urological conditions in late 1980s and prostate-specific antigen (PSA) testing in the early 1990s (Brewster et al, 2000). Higher incidence has been observed among men with better socioeconomic circumstances and educational attainment (Lund Nilsen et al, 2000). Similarly, increase in incidence of prostate cancer among more affluent men in the late 1990s was attributed to their greater exposure to PSA testing in England and Wales (Rowan, 2007). A recent report from the European Randomised Study of Screening for Prostate Cancer suggested that men in the PSA-based screening arm of the trial were significantly more likely to have low-risk disease, and during 11 years follow-up, they were more likely to experience significantly reduced mortality from prostate cancer (Schroder et al, 2012). It might be expected, and hoped, that

*Correspondence: Dr K Shafique; E-mail: k.shafique. I @research.gla.ac.uk Received 6 February 2012; revised I June 2012; accepted 8 June 2012; published online 3 July 2012 greater use of PSA testing would identify prostate cancers at an earlier stage than would otherwise be diagnosed symptomatically. Thus, both temporal increases in incidence and higher rates among more affluent populations might result in a stage shift towards less advanced disease. The increase in prostate cancer incidence in southeast England between 1990 and 1996 was restricted to localised tumours only, consistent with such an explanation (Evans and Moller, 2003). Similarly, SEER data from the USA showed an association between the socio-economic and educational attainment, and incidence, although an inverse association with stage at presentation (Clegg et al, 2009). However, in Finland, a higher rate of incidence in men from higher social classes was found for both localised and non-localised disease, suggesting that increased screening and diagnostic sensitivity was unlikely to wholly explain the difference. Paradoxically, socioeconomic differentials in incidence of non-localised prostate cancers disappeared over time, whereas differentials in localised disease persisted (Pukkala and Weiderpass, 2002). Thus, there remains uncertainty about the extent to which greater diagnostic sensitivity explains increases in prostate cancer incidence overall, or the relatively higher rate among more affluent men.

The incidence of prostate cancer continued to rise by $15 \%$ in the 10 years to 2009 in Scotland, UK (Information Services Division, 2011), making it important to understand better whether diagnostic artefacts or true increases in potentially modifiable risk 
factors were responsible. Our aim was to describe the overall and grade-specific temporal patterns of prostate cancer incidence by socio-economic circumstances in the West of Scotland over a 17-year period to the most recently available data.

\section{MATERIALS AND METHODS}

The West of Scotland has a male population of 1.2 million and comprises 4 National Health Service (NHS) Health Board areas: Ayrshire and Arran, Forth Valley, Greater Glasgow, and Clyde and Lanarkshire. Health care is almost exclusively provided through the NHS primary, secondary and tertiary services, which are taxfunded and free at the point of use. The population is racially homogeneous, comprising $98.0 \%$ White ethnic groups (Office of the Chief Statistician, 2004). Incident cases of prostate cancer from the West of Scotland were extracted from the Scottish Cancer Registry from 1991 to 2007, using the International Classification of Diseases version 10 codes for prostate cancer. Extracted data fields included data of birth, Gleason score of disease grade and the 2001 DEPCAT. The DEPCAT is a validated categorical version of the Carstairs score and ranks residential postcodes from 1 (most affluent) to 7 (most deprived), using 4 Census variables that were found to best predict health outcomes - car ownership, unemployment, overcrowding and lower occupational social class (IV and V) (Carstairs and Morris, 1990). They were further grouped into 3 conventional categories: 1 and 2 (affluent); 3-5 (intermediate); and 6 and 7 (deprived). The 2001 age and DEPCAT-specific population estimates for the West of Scotland were obtained from the General Registry Office for Scotland.

\section{Statistical analysis}

Age-standardised incidence rates were calculated by direct standardisation to the European Standard Population (Waterhouse et al, 1976) to control for differences in the age structure of the population between deprivation groups and over time. For the calculation of age-standardised rates, we stratified age into groups, that is, $<60$ years, $60-64$ years, and 5-year age groups thereafter up to 75-79 years, with the oldest group comprising patients aged $\geqslant 80$ years. All rates are presented as the European Age-Standardised Rates (EASR) per 100000 cases, with $95 \%$ confidence intervals (CI) where appropriate. Annual deprivation and disease grade-specific (from 1997) incidence rates were subsequently calculated. The rates were also calculated in three time periods (1991-1996; 1997-2002; 2003-2007) to reduce the effects of year-to-year random variation due to small numbers. These periods were chosen to separate the period for which Gleason grade was not available (before 1997) from two later periods when it was. Data on Gleason score were available from the cancer registry. The Scottish Cancer Registry began recording Gleason score from 1 January 1997, and therefore, the analysis of grade-specific incidence was restricted to 1997 onwards.

Incidence trends over time were calculated using joinpoint regression analysis. This analysis detects the point of time at which significant changes occurred in the age-standardised incidence rates (Kim et al, 2000). We allowed a maximum of three join points for estimations. Annual percentage changes and their corresponding $95 \% \mathrm{CI}$ and $P$-values were also calculated.

The EASR ratio was calculated by dividing the EASR of each deprivation group with the corresponding EASR of the leastdeprived group. A crude estimation, of the number of how many extra or fewer cases for each deprivation group, was done as the difference between the original number of incidence cases and the estimated number of incidence cases had each deprivation group the EASR of the least deprived group.

Weighted ordinary least-square linear regression was used to model EASRs for the deprivation categories. The estimated deprivation gap and corresponding CIs were calculated using the modelled EASR for the most deprived minus the modelled EASR for least-deprived category (National Cancer Intelligence Network, 2011). We calculated the excess cases and deprivation gap for overall as well as grade-specific prostate cancer incidence.

\section{RESULTS}

A total of 15519 incident cases of prostate cancer were registered in the West of Scotland from 1991 to 2007. Of those, 10985 cases were diagnosed after 1996, of which 6298 (57.3\%) had low Gleason grade, 3349 (30.5\%) had high Gleason grade and 1338 (12.2\%) had unknown Gleason grades. Mean age at incidence was 72.3 years (s.d. 9.0 years, range 26-101 years), and more than a quarter of patients lived in the most socio-economically deprived areas. Men in high-grade disease group were 3.34 years older at the time of diagnosis (mean age $73.6 \pm 9.2$ years) compared with men in the low-grade disease group (mean age $70.2 \pm 8.5$ years). The study period (1991-2007) was categorised into three groups: 1991-1996,

Table I Baseline characteristics of prostate cancer patients registered in the West of Scotland from I99I to 2007

\begin{tabular}{|c|c|c|c|c|c|c|c|}
\hline & \multicolumn{6}{|c|}{ Period of diagnosis } & \multirow[b]{3}{*}{$P$-value } \\
\hline & \multicolumn{2}{|c|}{$1991-1996$} & \multicolumn{2}{|c|}{$1997-2002$} & \multicolumn{2}{|c|}{$2003-2007$} & \\
\hline & All patients, $n$ & $\%$ & All patients, $n$ & $\%$ & All patients, $n$ & $\%$ & \\
\hline Total registered cases & 4534 & 29.2 & 5506 & 35.5 & 5479 & 35.3 & \\
\hline \multicolumn{8}{|l|}{ Age at incidence } \\
\hline Age $<65$ years & 683 & |5.| & 1027 & 18.7 & 1286 & 23.5 & $<0.001$ \\
\hline Age $65-74$ years & 1753 & 38.7 & 2106 & 38.3 & 2209 & 40.3 & \\
\hline Age $\geqslant 75$ years & 2098 & 46.3 & 2373 & 43.1 & 1984 & 36.2 & \\
\hline \multicolumn{8}{|l|}{ Gleason grade } \\
\hline Gleason $\leqslant 7$ & - & - & 3033 & 55.1 & 3265 & 59.6 & $<0.001$ \\
\hline Gleason 8-10 & - & - & 1556 & 28.3 & 1793 & 32.7 & \\
\hline Unknown Gleason & - & - & 917 & 16.7 & 421 & 7.7 & \\
\hline \multicolumn{8}{|l|}{ Socio-economic circumstances } \\
\hline Affluent (Depcat I, 2) & 785 & 17.3 & 1028 & 18.7 & 1110 & 20.3 & $<0.001$ \\
\hline Intermediate (Depcat 3, 4, 5) & 2465 & 54.4 & 3052 & 55.4 & 3150 & 57.5 & \\
\hline Deprived (Depcat 6, 7) & 1284 & 28.3 & 1426 & 25.9 & 1219 & 22.3 & \\
\hline
\end{tabular}

Period of diagnosis was based on incidence date recorded in cancer registry; $P$-values calculated by $\chi^{2}$-test. 
1997-2002 and 2003-2007. Significant differences in demographic and disease characteristics of patients were observed between these periods (Table 1). Mean age at incidence fell over the study period from 73.4 years during 1991-1996 to 71.2 years during 2003-2007 $(P<0.001)$. Where Gleason grade was available, the proportion of unknown grades fell from $16.7 \%$ in $1997-2002$ to $7.7 \%$ in 2003-2007. There was a progressive trend towards greater proportions of affluent patients over time.

\section{Temporal trend analysis}

The EASR of prostate cancer increased during the study period from 44 per 100000 cases in 1991 to 75 per 100000 cases in 2007. This $70 \%$ overall increase represents a mean annual growth of
3.6\% (Figure 1A and Table 2). The temporal increase was greatest at younger ages. Incidence rates increased by $200 \%$ among the youngest men (aged $<65$ years) from 7 to 21 per 100000 cases between 1991 and 2007 - an average annual growth of 7.5\% whereas $75 \%$ and $50 \%$ increases in EASR were observed for men of age 65-74 years and $\geqslant 75$ years, respectively. Both high- and lowgrade prostate cancers increased (Table 2, Figure 2A). The mean EASR was 67 per 100000 cases in 1997 to 2002 and increased to 81 per 100000 cases in 2003-2007. Joinpoint analysis identified statistically significant temporal increases in low-grade tumours of 7.9\% per year (95\% CI 4.3-11.5) between 1997 and 2004, and in high-grade tumours of $7.6 \%$ per year (95\% CI 2.6-12.8) between 2000 and 2007. These changes are further illustrated in Figure 2B. The ratio of low- to high-grade tumours was about 2 for most of
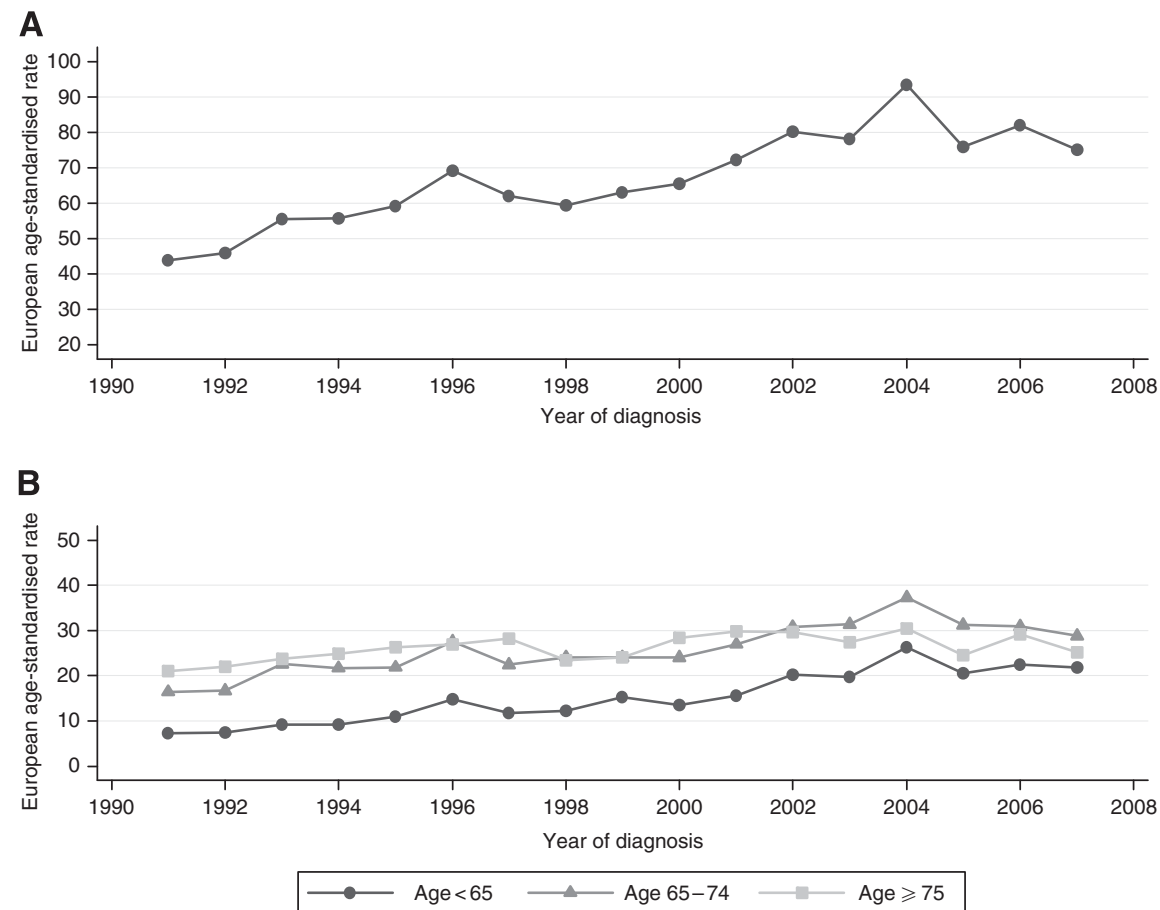

Figure I (A) Overall age-standardised and (B) age-specific incidence rates of prostate cancer in the West of Scotland, 199I-2007.

Table 2 Trends of prostate cancer incidence by disease grade and socio-economic circumstances from |99| to 2007: joinpoint analysis

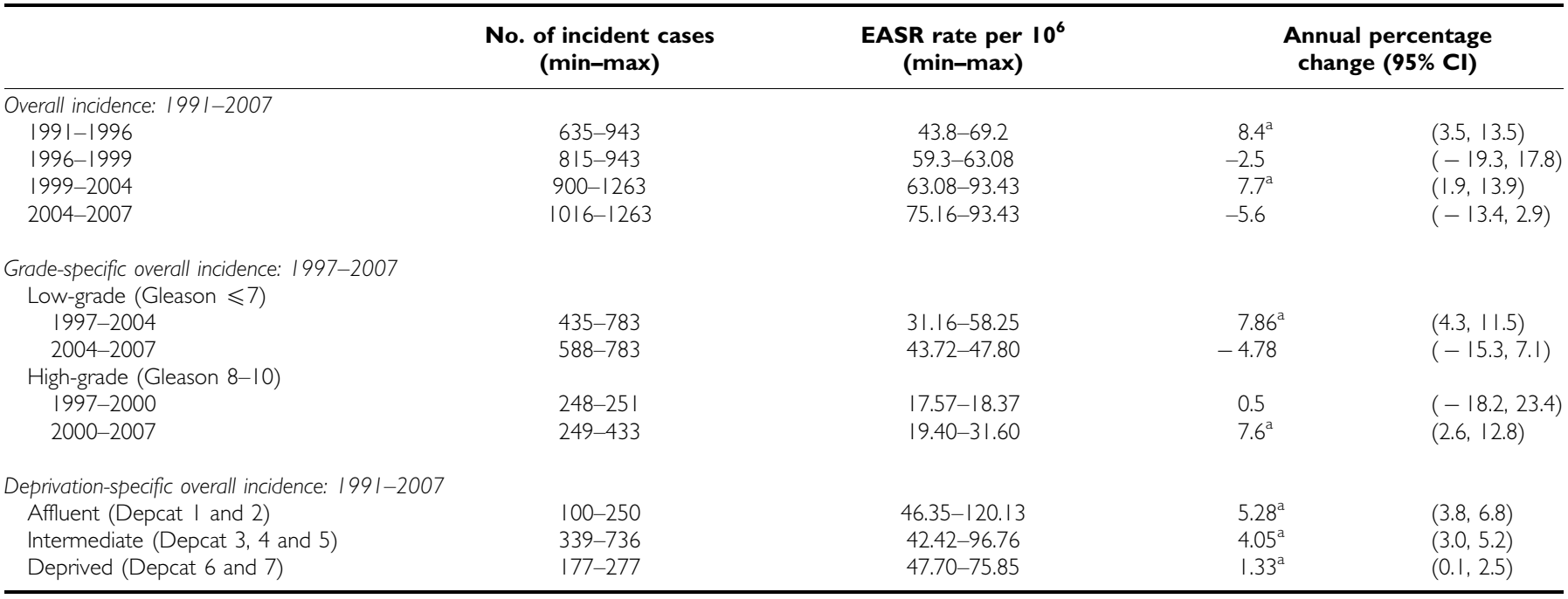

Abbreviations: $\mathrm{EASR}=$ European age-standardised rate; $\mathrm{Cls}=$ confidence intervals. ${ }^{\mathrm{a}}$ The average annual per cent change is statistically significant from 0. 
A

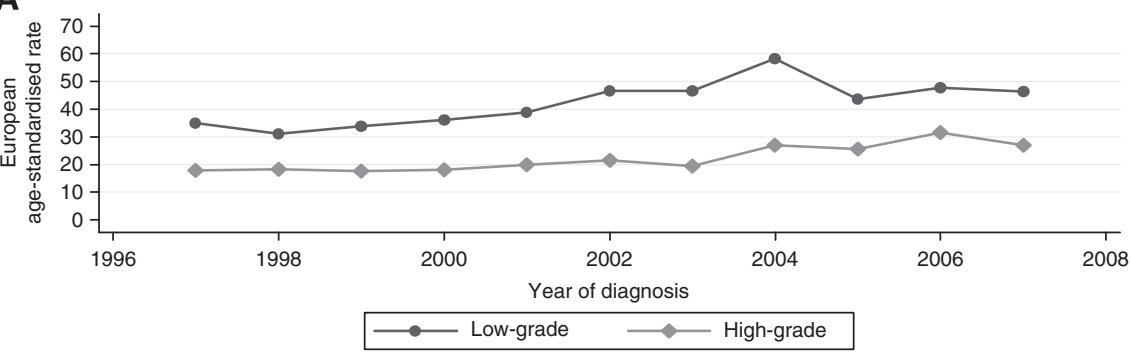

B

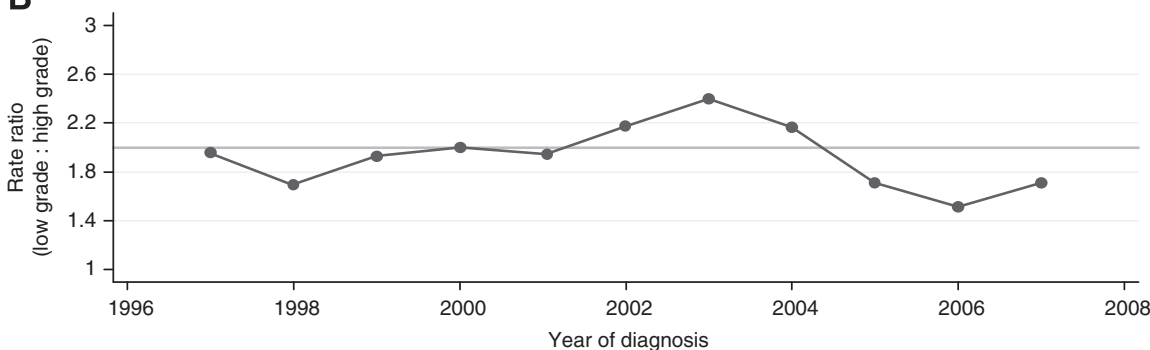

Figure 2 (A) Overall grade-specific prostate cancer incidence and (B) rate ratio of grade-specific age-standardised incidence rates (low-grade (Gleason $\leqslant 7$ ): high-grade (Gleason 8-10)) in the West of Scotland, 1997-2007.
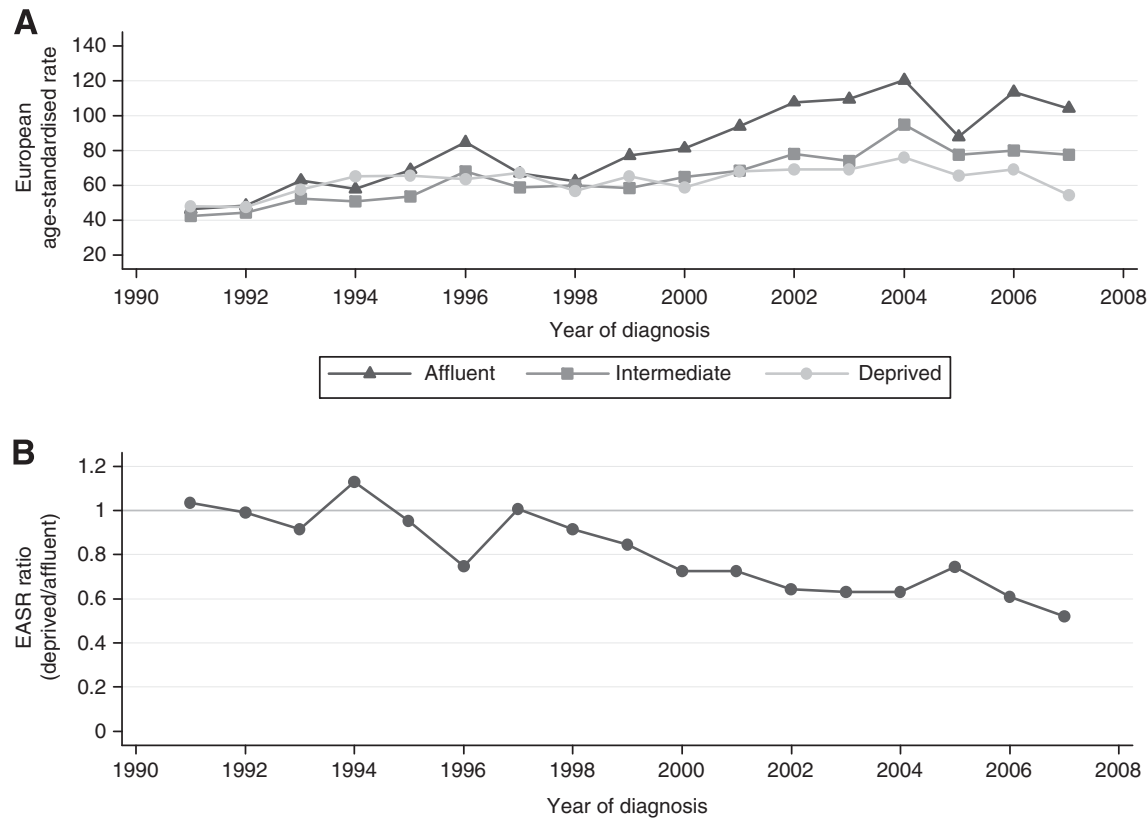

Figure 3 Age-standardised incidence rates of prostate cancer by socio-economic circumstances in the West of Scotland, 199I-2007. (A) deprivationspecific, (B) rate ratio (deprived: affluent).

the study period (Figure 2B). Between 2002 and 2004, there was a slightly higher proportion of low-grade tumours, but between 2005 and 2007, there was a lower proportion of them.

Over time, the incidence of prostate cancer increased for all socio-economic groups; however, the largest increase, with an average annual increase of 5.3\% (95\% CI 3.8-6.8), was among the most affluent group, whereas the smallest increase of $1.3 \%$ (95\% CI $0.1-2.5$ ) was observed among the most deprived group (Table 2 and Figure 3A). This socio-economic gap between incidence rates started appearing after 1998, before which rates were similar (Figure 3B). This can be more clearly interpreted from the ratio of EASRs (between deprived and affluent); the incidence ratio remained approximately 1 between 1991 and 1998, but fell progressively to 0.5 in 2007 (Figure 3B).
The socio-economic patterns of prostate cancer incidence are separately described for low- and high-grade disease in Figures $4 \mathrm{~A}$ and $\mathrm{B}$, respectively. For low-grade disease, incidence increased over time to a greater extent with increasing affluence, creating a significant difference between socio-economic groups $(P$-value $=0.002)$. For high-grade disease; however, there was no clear difference in incidence between socio-economic groups over time $(P$-value $=0.15)$

\section{Deprivation gap}

Between 1991 and 1996, there was no significant difference in prostate cancer incidence between affluent and deprived men $(P=0.76$; trend) (Table 3). From 1997 to 2002, the incidence 
A



B



Figure 4 (A) Low-grade (Gleason $\leqslant 7$ ) disease by socio-economic status in the West of Scotland, 199|-2007; and (B) high-grade (Gleason 8-10) disease by socio-economic status in the West of Scotland, |99|-2007.

Table 3 Deprivation gap in incidence of prostate cancer from 1991 to 2007 in the West of Scotland

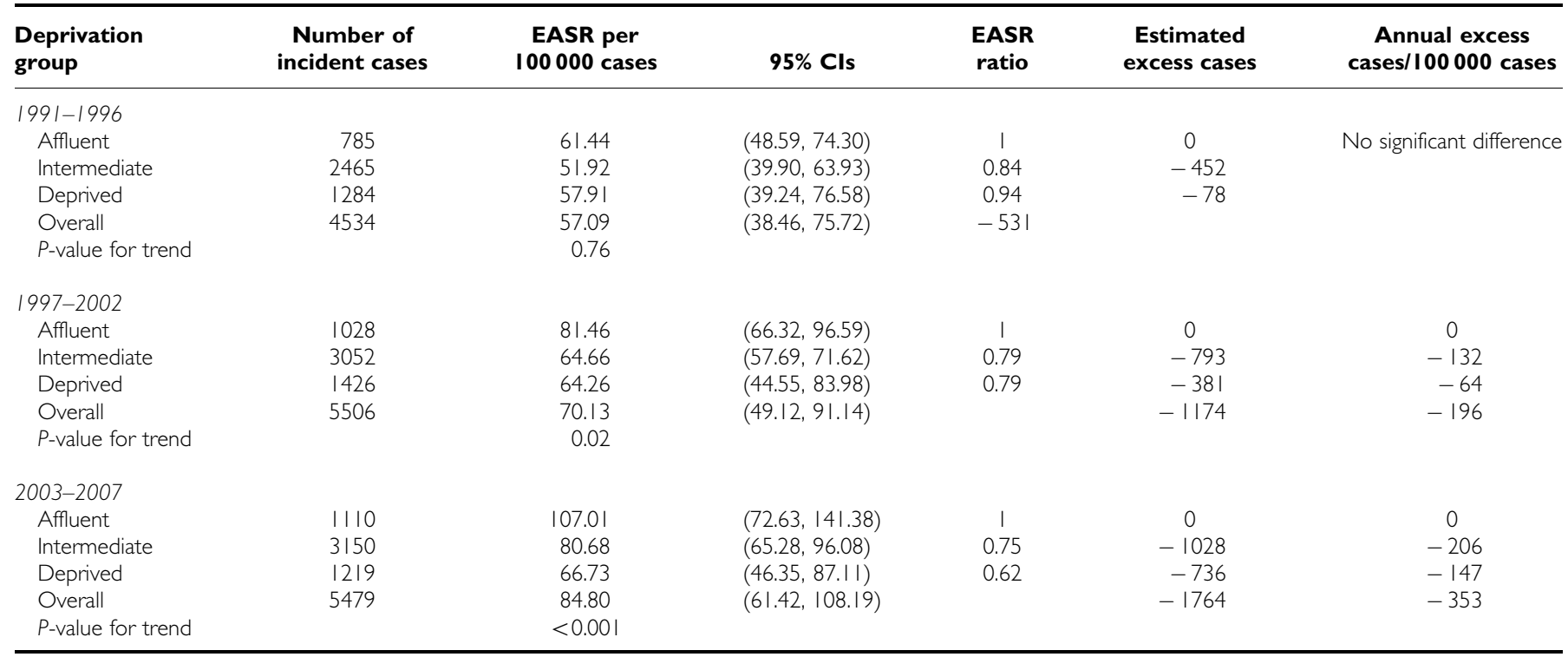

Abbreviations: $\mathrm{EASR}=$ European age-standardised rate; $\mathrm{Cls}=$ confidence intervals.

among the most affluent was 81.5 per 100000 cases compared with 64.3 per 100000 cases in the most deprived, giving a deprivation gap as an absolute difference of 17.2 per 100000 cases $(P=0.02$; trend; Table 3). This deprivation gap widened to 40.3 per 100000 cases in the most recent period (2003-2007), because of a relatively greater increase in incidence among the most affluent. An estimated 353 more cases of prostate cancer per year would be diagnosed in the West of Scotland if all socio-economic groups had the same incidence rate as those of the most affluent during 2003-2007.

Socio-economic and disease grade-specific incidence rates were analysed from 1997 to 2007. From 1997 to 2002, the incidence of low-grade disease among the most affluent was 41.8 per
100000 cases compared with 34.9 per 100000 cases in the most deprived, giving a deprivation gap as an absolute difference of 6.9 per 100000 cases $(P=0.07$, trend; Table 4$)$. This deprivation gap widened in the most recent period (2003-2007), with an incidence among the affluent men of 56.2 per 100000 cases compared with 45.7 per 100000 cases in the most deprived, a deprivation gap of 10.5 per 100000 cases $(P<0.001$; trend). An estimated 93 more cases of low-grade prostate cancer per year would be diagnosed in the West of Scotland if the socio-economic groups had the same incidence rate as of affluent group during 2003-2007. We did not observe any significant deprivation gap for high-grade tumours in either period. 
Table 4 Deprivation gap in grade-specific prostate cancer incidence from 1997 to 2007 in the West of Scotland

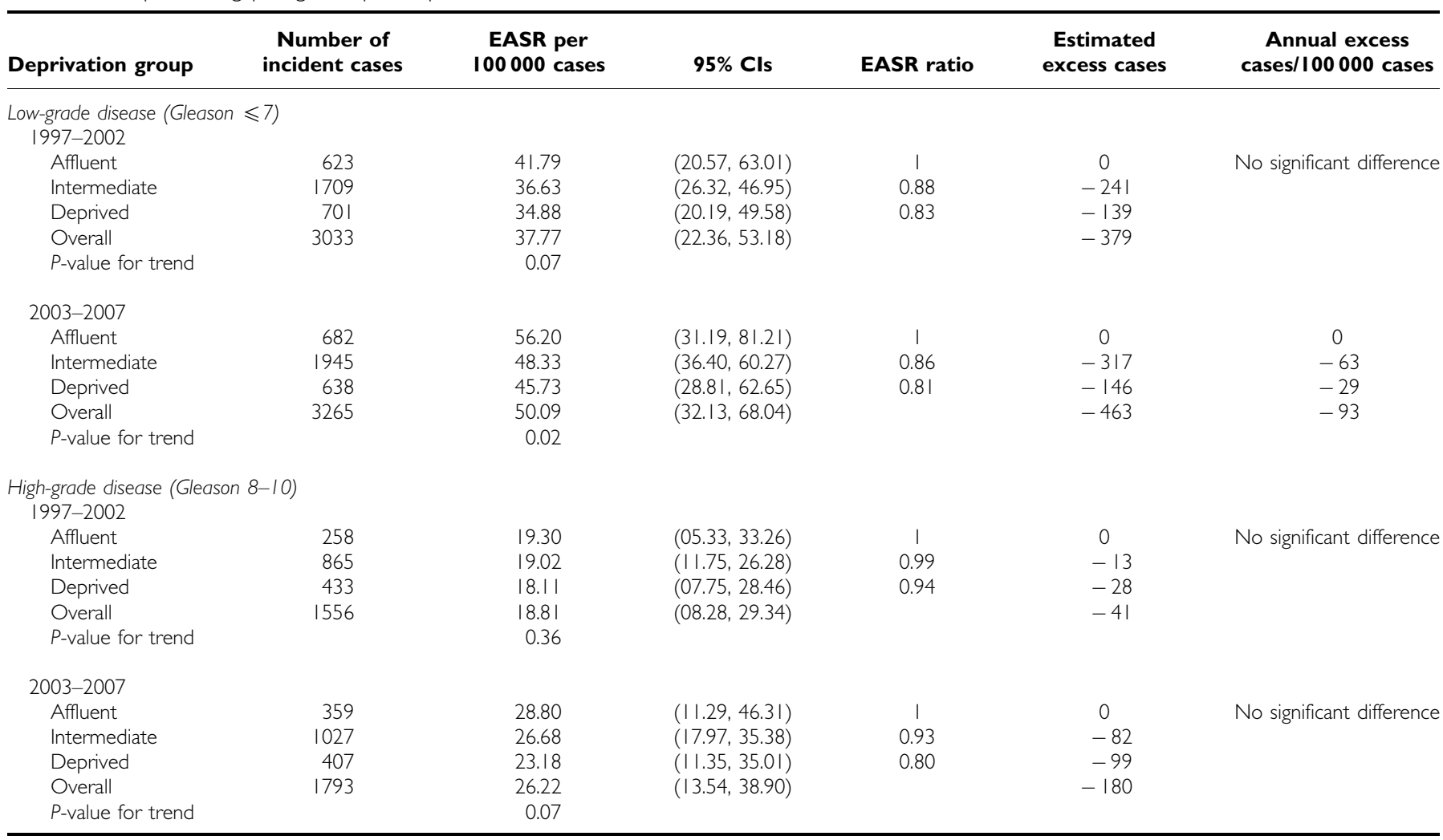

Abbreviations: $\mathrm{EASR}=$ European age-standardised rate; $\mathrm{Cls}=$ confidence intervals.

\section{DISCUSSION}

The increase in incidence of prostate cancer in the West of Scotland between 1991 and 2007 was not accompanied by a 'grade shift' towards lower-grade disease that might have suggested PSA testing was responsible. A true increase in incidence remains a plausible explanation. The largest increase in incidence occurred in men under the age of 65 years. Such a pattern has been attributed to PSA testing in England (Moore et al, 2009), but in the absence of any evidence about age-specific use of PSA testing in our study population, we cannot propose that this is likely. Prostate cancer incidence increased in all socio-economic groups over time, but low-grade disease increased more in the most affluent groups. This produced a socio-economic gradient in incidence from 1998 onwards. Although this is consistent with greater diagnostic sensitivity in more affluent populations, however, there was no convincing evidence of a consistent relatively greater increase in incidence of low-grade disease over time.

Steep increases in incidence of prostate cancer have also been observed elsewhere (Evans and Moller, 2003; Westlake and Cooper, 2008; Bray et al, 2010). These have been attributed to screening of older or younger individuals by PSA testing (Collin et al, 2008; Moore et al, 2009; Bray et al, 2010). The steep increase in incidence of prostate cancer in our study may also be a result of opportunistic PSA testing, which started in 1989 in Scotland (Brewster et al, 2000). Socio-economic differences in the incidence of prostate cancer have also been reported in the West Midlands, England (Dutta et al, 2005). Material deprivation may affect incidence of prostate cancer in a number of ways. The preferred explanation by most authors is that, because prostate cancer is a ubiquitous disease affecting the majority of men beyond middle age (Haas et al, 2008), any factor that increases likelihood of detection may appear to be a risk factor, when in fact it is only a source of observation bias. Evidence that men in more affluent circumstances are more likely to receive PSA and temporal trend of incidence are due to differential diagnostic sensitivity between deprivation groups remains anecdotal, however, further research is needed to confirm this suggestion.

If the association between deprivation and prostate cancer is truly causal, it may be due to differences in exposures to modifiable risk factors, such as the protective effects of food containing lycopene or the increased risks associated with diets that are high in calcium (American Institute for Cancer Research and World Cancer Research Fund, 2007). We are not aware of evidence to suggest that socio-economic differentials in relevant dietary factors have emerged during the induction periods for the prostate cancer we report here. Finally, because of the strong association between increasing age and prostate cancer incidence, higher rates of competing causes of death in men from more deprived circumstances may remove them from the at-risk period in later life (Grundmark et al, 2010). As prostate cancer is often a slow-growing indolent disease, such an effect may be another form of observation bias.

A socio-economic difference in prostate cancer incidence emerged from 1998 onwards. Prostate cancer incidence rates were 17.2 per 100000 cases higher in affluent compared with deprived populations in 1997-2002, and increased to 40.3 per 100000 cases in 2003-2007. Such differences translate into 1764 cases, or $32 \%$ of all cases, which might have occurred, had intermediate and deprived populations had the same incidence as the most affluent. In the last two decades, the incidence of prostate cancer has increased among men in higher socio-economic groups, both in European countries as well as the United States (Liu et al, 2001; Westlake and Cooper, 2008; Yin et al, 2010).

Our study has strengths and weaknesses. We used incidence data from the Scottish Cancer Registry, which has a high level of completeness and accuracy (Brewster et al, 1994, 1995; Brewster and Stockton, 2008). The sample size was large enough to detect 
the significant differences in rates between subgroups of the population. Individual social class data were not available, but the Carstairs score(Carstairs and Morris, 1990) has been widely used to describe the socio-economic patterns in cancer incidence and survival (Shack et al, 2007; National Cancer Intelligence Network, 2011). Some recent evidence from Ireland suggests that the choice of an aggregated index for socio-economic circumstances or income-based deprivation measure makes no significant difference to relative inequalities in prostate cancer incidence (Donnelly and Gavin, 2011). As with all area-based measures of deprivation, however, it assumes that all the individuals living in a given geographical area experience the same level of deprivation and associated cancer risk factors. This form of information bias, the ecological fallacy, is inherent in area-based measures of socioeconomic circumstances, but where both individuals and areabased measures have been available, results have been consistent (Davey Smith et al, 1998). We observed a 9\% reduction in unknown grade disease in 2003-2007 compared with unknown grade disease in 1997-2002. The rise in the overall incidence rate and an absence of a consistent shift toward lower- or higher-grade disease suggests that our findings have not been subject to significant reporting biases. Information on tumour stage, such a TNM, was not available, and we therefore used Gleason grade.

The present study indicates that there are large socio-economic variations in the occurrence of prostate cancer in the West of Scotland. It remains unclear whether the high rates of low-grade disease among affluent men are due to greater use of PSA testing, and if so, whether earlier detection results in better outcomes or overdiagnosis. Previous research indicated that only $16 \%$ of asymptomatic men detected by a screening test would benefit from radical treatments and their disease, otherwise they would not have compromised their life expectancy and quality of life (Frankel et al, 2003). Early detection of prostate cancer might not lead to radical treatment, but result in serious psychological consequences and impact on quality of life after diagnosis.

\section{REFERENCES}

American Institute for Cancer Research, World Cancer Research Fund (2007) Food, Nutrition, Physical Activity, and the Prevention of Cancer: A Global Perspective. American Institute for Cancer Research: Washington

Ben-Shlomo Y, Evans S, Ibrahim F, Patel B, Anson K, Chinegwundoh F, Corbishley C, Dorling D, Thomas B, Gillatt D, Kirby R, Muir G, Nargund V, Popert R, Metcalfe C, Persad R (2008) The risk of prostate cancer amongst black men in the United Kingdom: the PROCESS cohort study. Eur Urol 53: 99-105

Bray F, Lortet-Tieulent J, Ferlay J, Forman D, Auvinen A (2010) Prostate cancer incidence and mortality trends in 37 European countries: An overview. Eur J Cancer 46: 3040-3052

Brewster D, Crichton J, Muir C (1994) How accurate are Scottish cancer registration data? Br J Cancer 70: 954-959

Brewster D, Muir C, Crichton J (1995) Registration of colorectal cancer in Scotland: an assessment of data accuracy based on review of medical records. Public Health 109: 285-292

Brewster DH, Fraser LA, Harris V, Black RJ (2000) Rising incidence of prostate cancer in Scotland: increased risk or increased detection? BJU Int 85: 463-472

Brewster DH, Stockton DL (2008) Ascertainment of breast cancer by the Scottish Cancer Registry: an assessment based on comparison with five independent breast cancer trials databases. Breast 17: 104-106

Carstairs V, Morris R (1990) Deprivation and health in Scotland. Health Bull (Edinb) 48: 162-175

Clegg LX, Reichman ME, Miller BA, Hankey BF, Singh GK, Lin YD, Goodman MT, Lynch CF, Schwartz SM, Chen VW, Bernstein L, Gomez SL, Graff JJ, Lin CC, Johnson NJ, Edwards BK (2009) Impact of socioeconomic status on cancer incidence and stage at diagnosis: selected findings from the surveillance, epidemiology, and end results: National Longitudinal Mortality Study. Cancer Causes Control 20: $417-435$

\section{CONCLUSION}

An increase in low grade-disease in affluent men may suggest that PSA testing is responsible, but it does not fully explain the overall increases in all grades of disease. Potentially modifiable risk factors may be responsible for a true increase in prostate cancer occurrence. Further research is needed to determine the agespecific and socio-economic patterns of PSA testing in the UK populations.

\section{ACKNOWLEDGEMENTS}

We thank Philip McLoone for his statistical advice and Billy Sloan for data extraction.

\section{Conflict of interest}

The authors declare no conflict of interest.

\section{Author contributions}

All authors designed the study; KS carried out statistical analyses; all authors contributed to interpreting the results; KS and DSM drafted the manuscript; all authors saw and approved the final manuscript. DSM is guarantor.

\section{Disclaimer}

All authors were paid by their employer. Employer had no role in the design, collection, analysis, interpretation of data, in writing of manuscript or decision to submit the manuscript for publication.

Collin SM, Martin RM, Metcalfe C, Gunnell D, Albertsen PC, Neal D, Hamdy F, Stephens P, Lane JA, Moore R, Donovan J (2008) Prostatecancer mortality in the USA and UK in 1975-2004: an ecological study. Lancet Oncol 9: 445-452

Davey Smith G, Hart C, Watt G, Hole D, Hawthorne V (1998) Individual social class, area-based deprivation, cardiovascular disease risk factors, and mortality: the Renfrew and Paisley Study. J Epidemiol Comm Health 52: 399-405

Donnelly DW, Gavin A (2011) Socio-economic inequalities in cancer incidence - the choice of deprivation measure matters. Cancer Epidemiol 35: e55-e61

Dutta RS, Philip J, Javle P (2005) Trends in prostate cancer incidence and survival in various socioeconomic classes: a population-based study. Int J Urol 12: 644-653

Evans HS, Moller H (2003) Recent trends in prostate cancer incidence and mortality in southeast England. Eur Urol 43: 337-341

Frankel S, Smith GD, Donovan J, Neal D (2003) Screening for prostate cancer. Lancet 361: 1122-1128

Grundmark B, Garmo H, Loda M, Busch C, Holmberg L, Zethelius B (2010) The metabolic syndrome and the risk of prostate cancer under competing risks of death from other causes. Cancer Epidemiol Biomark Prev 19: 2088-2096

Haas GP, Delongchamps N, Brawley OW, Wang CY, de la Roza G (2008) The worldwide epidemiology of prostate cancer: perspectives from autopsy studies. Can J Urol 15: 3866-3871

Information Services Division, NHS, National Services Scotland (2011) Cancer in Scotland. Information Services Division, NHS National Services Scotland: Edinburgh

Johns LE, Houlston RS (2003) A systematic review and meta-analysis of familial prostate cancer risk. BJU Int 91: 789-794

Kim HJ, Fay MP, Feuer EJ, Midthune DN (2000) Permutation tests for joinpoint regression with applications to cancer rates. Stat Med 19: 335-351 
Liu L, Cozen W, Bernstein L, Ross RK, Deapen D (2001) Changing relationship between socioeconomic status and prostate cancer incidence. J Natl Cancer Inst 93: 705-709

Lund Nilsen TI, Johnsen R, Vatten LJ (2000) Socio-economic and lifestyle factors associated with the risk of prostate cancer. $\mathrm{Br} J$ Cancer 82: 1358-1363

Moore AL, Dimitropoulou P, Lane A, Powell PH, Greenberg DC, Brown CH, Donovan JL, Hamdy FC, Martin RM, Neal DE (2009) Population-based prostate-specific antigen testing in the UK leads to a stage migration of prostate cancer. BJU Int 104: 1592-1598

National Cancer Intelligence Network (2011) Cancer incidence by deprivation England, 1995-2004 http://www.ncin.org.uk/publications/ reports/default.aspx (accessed on 10 November 2011).

Office of the Chief Statistician (2004) Analysis of Ethnicity in the 2001 Census. Summary report.Scottish Executive: Edinburgh

Pukkala E, Weiderpass E (2002) Socio-economic differences in incidence rates of cancers of the male genital organs in Finland, 1971-1995. Int J Cancer 102(6): 643-648

Rowan S (2007) Trends in cancer incidence by deprivation, England and Wales, 1990-2002. Health Stat Quart Off Natl Stat 36: 24-35
Sakr WA, Grignon DJ, Haas GP, Heilbrun LK, Pontes JE, Crissman JD (1996) Age and racial distribution of prostatic intraepithelial Neoplasia. Eur Urol 30: 138-144

Schroder FH, Hugosson J, Roobol MJ, Tammela TL, Ciatto S, Nelen V, Kwiatkowski M, Lujan M, Lilja H, Zappa M, Denis LJ, Recker F, Paez A, Maattanen L, Bangma CH, Aus G, Carlsson S, Villers A, Rebillard X, van der Kwast T, Kujala PM, Blijenberg BG, Stenman UH, Huber A, Taari K, Hakama M, Moss SM, de Koning HJ, Auvinen A (2012) Prostate-cancer mortality at 11 years of follow-up. $N$ Engl J Med 366: 981-990

Shack LG, Rachet B, Brewster DH, Coleman MP (2007) Socioeconomic inequalities in cancer survival in Scotland 1986-2000. Br J Cancer 97: 999-1004

Waterhouse JAH, Muir CS, Correa P, Powell J (1976) A New Measure of Age Standardized Incidence. The Cumulative Rate. In Cancer Incidence in Five Continents Vol. IIIIARC Scientific Publications No.15. International Agency for Research on Cancer: Lyon

Westlake S, Cooper N (2008) Cancer incidence and mortality: trends in the United Kingdom and constituent countries, 1993-2004. Health Stat Quarter Off Natl Stat 38: 33-46

Yin D, Morris C, Allen M, Cress R, Bates J, Liu L (2010) Does socioeconomic disparity in cancer incidence vary across racial/ethnic groups? Cancer Causes Control 21: 1721-1730

This work is published under the standard license to publish agreement. After 12 months the work will become freely available and the license terms will switch to a Creative Commons Attribution-NonCommercial-Share Alike 3.0 Unported License. 